\title{
Gestão de cuidados ao idoso dependente: Relato de um caso
}

\author{
Care management of the dependent elderly: A case report \\ Gestión de la atención a los ancianos dependientes: Relato de un caso clínico \\ Dalila Teixeira. Unidade Local de Saúde de Matosinhos (ULSM). Matosinhos, Distrito do Porto, Portugal. \\ dalilateixeira21@ hotmail.com (Autora correspondente)
}

\section{Resumo}

O presente caso enfatiza o papel do médico de família como gestor de cuidados assistenciais ao doente sem autonomia funcional; salientando-se a importância da abordagem sistêmica no planejamento da intervenção. Maria e José, ambos octogenários, formam uma família nuclear na fase VIII, do ciclo de Duvall. Na sequência de uma hospitalização prolongada, Maria ficou acamada, verificando-se na primeira visita domiciliar que José executava de forma praticamente isolada a função de cuidador. Perante esta situação, a médica de família coordenou uma rede apoios formais e informais, que permitiram aliviar a sobrecarga de José e a recuperação da capacidade de marcha de Maria. A relevância deste caso prende-se com o fato de constituir um exemplo paradigmático da atividade distintiva do médico de família, enquanto agente executor de uma abordagem globalizante, capaz de aglutinar os múltiplos aspectos fundamentais ao bem-estar integral dos doentes.

\section{Abstract}

This case emphasizes the role of the family doctor as a care manager for patients without functional autonomy, emphasizing the importance of a systemic approach to planning the intervention. José and Maria, both octogenarians, form a nuclear family in stage VIII of the Duvall cycle. Subsequent to a prolonged hospitalization, Maria became completely dependent on José for basic daily activities due to the loss of walking ability. During the first home visit after discharge, the family doctor verified that José had single-handedly taken over the role of Maria's caregiver. Faced with this situation, the family doctor coordinated a network of formal and informal support that reduced the workload on José and facilitated the recovery of Maria's walking ability. This case is important in showing the distinctive action of the family doctor as an executive agent of a holistic approach and one who is capable of bringing together various aspects integral to the well-being of patients.

\section{Resumen}

El presente caso subraya la importancia del papel del médico de familia como gestor de cuidados asistenciales al paciente sin autonomía funcional; destacándose la importancia del enfoque sistémico, en la planificación de la intervención. Maria y José, ambos octogenarios, forman una familia nuclear en la fase VIII, del ciclo de Duvall. A consecuencia de una hospitalización prolongada Maria se vio obligada a guardar cama, comprobándose en la primera visita domiciliar que José desempeñaba la función de cuidador prácticamente sin ayudas. Ante esta situación, lo médico de familia coordinó una red de apoyos formales e informales que se tradujo en un alivio de la sobrecarga de José y en la recuperación de la capacidad de marcha de Maria. La relevancia de este caso reside en que constituye un ejemplo paradigmático de la actividad distintiva del médico de familia, como agente ejecutor de un enfoque integrador y comprensivo, susceptible de aglutinar los múltiples aspectos fundamentales para el bienestar integral de los pacientes.

Como citar: Teixeira D. Gestão de cuidados ao idoso dependente: Relato de um caso. Rev Bras Med Fam Comunidade. 2016;11(38):1-7. http://dx.doi.org/10.5712/rbmfc11(38)1103
Palavras-chave: Atenção Primária à Saúde Idoso Dependência (Psicologia) Cuidados Médicos Medicina de Família e Comunidade

Keywords: Primary Health Care Aged Dependence (Psychology) Medical Care Family Practice

Palabras clave: Atención Primaria de Salud Anciano Dependencia (Psicología) Atención Médica Medicina Familiar y Comunitaria

Fonte de financiamento: declara não haver. Parecer CEP: não se aplica. Conflito de interesses: declara não haver. Procedência e revisão por pares: revisado por pares. Recebido em: 23/03/15. Aprovado em: 26/01/16. 


\section{Introdução}

O fenômeno mundial de crescimento da população idosa dependente,${ }^{1}$ associado à ausência de um número suficiente de estruturas e serviços de suporte, bem como a crescente desresponsabilização da família no cuidado aos seus membros dependentes tem criado crescentes dificuldades na gestão desta problemática. De fato, o surgimento de novos modelos de organização familiar decorrentes das mudanças estruturais, socioeconômicas e culturais na sociedade, tais como a organização social do trabalho, a entrada maciça da mulher no mercado de trabalho, a existência de novos valores socioculturais, as transformações de mentalidades, tem contribuído para a diminuição dos tempos dedicados ao trabalho e à partilha das responsabilidades familiares.

É, por isso, crescente o papel do médico de família na supervisão da funcionalidade da família, principalmente na presença de situações clínicas e/ou socioeconômicas complexas; bem como na promoção de medidas que promovam o seu amparo, numa ótica de prestação contínua de cuidados; premissas estas que nos remetem para a necessidade de ter acesso às famílias, de obter pleno conhecimento acerca deste "microssistema comunitário", numa lógica de identificar prioridades na assistência e planeamento de ações.

De fato e de acordo com Silva e Santos, ${ }^{2}$ trabalhar com famílias é uma arte que se desenvolve por meio da compreensão e exploração das estruturas familiares, com a finalidade de elaborar uma estratégia personalizada a cada conjunto familiar.

Tarefa esta que para profissionais cuja formação foi, e ainda é, prioritariamente técnica se revela difícil, pois o envolvimento com conflitos pessoais e situações psicossociais que influenciam no diagnóstico e tratamento da família, seja de forma consciente ou inconsciente, exige, além da capacidade técnica, a capacidade relacional, ou seja, um profissional de ajuda. ${ }^{3}$

É neste panorama que se define a importância que podem assumir instrumentos que proporcionem uma síntese dos dados das famílias, identificando dificuldades e facilidades em relação ao processo saúde-doença. ${ }^{4}$

Pretende-se, assim, descrever um caso paradigmático, desta crescente realidade, no sentido de suscitar uma reflexão nos profissionais de saúde, relativamente ao crescente desafio que o cuidar do idoso dependente no paradigma da desinstitucionalização representa. Salientando-se a necessidade de implementar uma abordagem holística, com exploração/avaliação sistemática do contexto sociofamiliar do idoso, apoiada num referencial teórico, capaz de identificar e mobilizar os recursos necessários à prestação de cuidados assistenciais ao doente sem autonomia, como estratégia fundamental para garantir o seu bem-estar e dignidade.

Descrita na literatura como a relação mais importante na meia-idade e velhice, a importância da relação marital no caso que se descreve obrigou a uma abordagem do casal como uma unidade.

\section{Identificação}

Maria e José (nomes fictícios) de 86 e 81 anos, respectivamente, formam um casal há mais de 6 décadas. Ambos residentes numa cidade do norte de Portugal, há vários anos, constituem atualmente uma família nuclear na fase VIII, do ciclo de Duval. Durante a sua vida ativa, Maria dedicou-se à vida doméstica; José, por sua vez, trabalhou como operário fabril. 


\section{Estado cognitivo e funcional}

José mantém-se cognitivamente íntegro e totalmente independente nas atividades instrumentais de vida diária, exceto a dificuldade na gestão da medicação. Em contrapartida, Maria, na sequência da evolução da sua doença demencial (Mini Mental State = 7 pontos), apresenta-se dependente nas atividades básicas de vida diária. Mantém, no entanto, capacidade de marcha preservada, com apoio de uma bengala.

\section{Contexto econômico}

O casal vive em casa própria, num primeiro andar, sem elevador, dotada de água canalizada, eletricidade e saneamento básico. A aposentadoria de José constitui a única fonte de rendimento do casal, suficiente apenas para suprir as necessidades básicas (índice de Grafar 17 - Classe média).

\section{Contexto sociofamiliar}

O casal vive sozinho, estabelecendo uma relação distante com os 4 filhos, apesar de coabitarem na mesma cidade, dos quais praticamente não recebe qualquer tipo de suporte. Não existem igualmente relações significativas com vizinhos ou amigos.

José e Maria frequentam, há 5 anos, um Centro de Dia, espaço onde foram bem acolhidos e integrados. Este centro excede as funções de um espaço de convívio e estímulo, assumindo responsabilidade nos cuidados alimentares do casal, e, no caso específico de Maria, os cuidados de higiene. Esta entidade exerce ainda um papel essencial de auxílio na gestão da terapêutica, aspecto no qual José revelava grandes dificuldades e que foi suprido pelo contato que a médica de família estabeleceu com a responsável do Centro de Dia, solicitando o seu envolvimento nessa função. Sendo estas duas entidades - Centro de Saúde e Centro de Dia, que José considera ser a principal fonte de apoio (Figure 1 e Tabela 1).

\section{Escalas/Instrumentos de avaliação familiar}

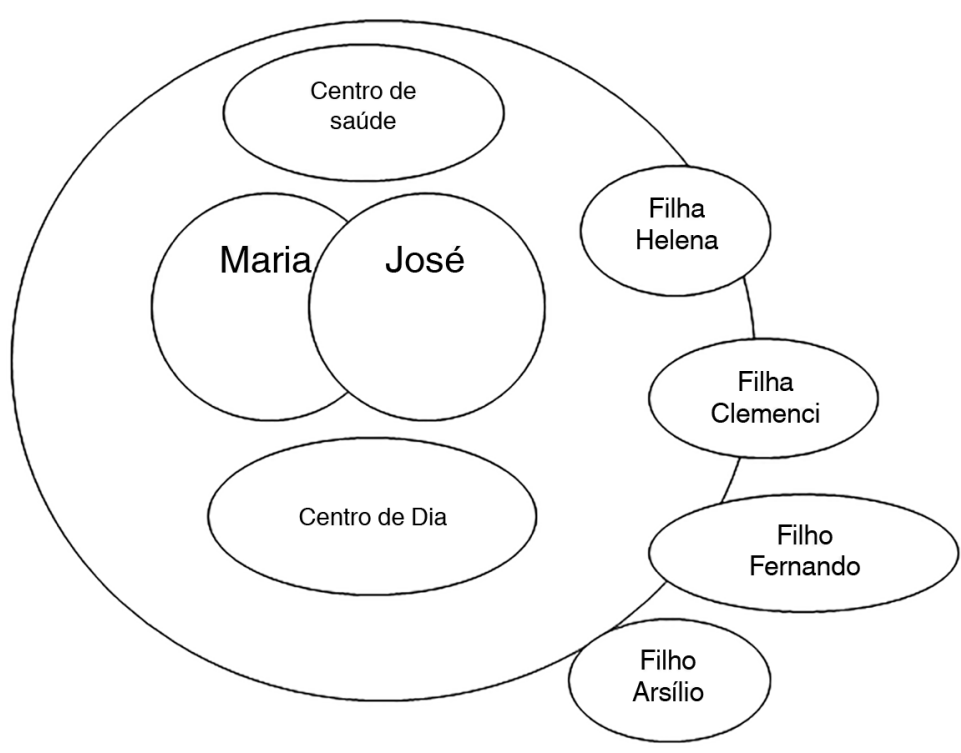

Figura 1. Ecomapa. 
Tabela 1. Apgar familiar.

\begin{tabular}{|c|c|c|c|}
\hline & Apgar familiar & Sempre (2) Às vezes (1) & Nunca (0) \\
\hline Adaptação & $\begin{array}{l}\text { Estou satisfeito com a ajuda que recebo da minha família sempre que } \\
\text { alguma coisa me preocupa }\end{array}$ & & $\mathrm{X}$ \\
\hline Comunicação & $\begin{array}{l}\text { Estou satisfeito pela forma como a minha família discute assuntos de } \\
\text { interesse comum e partilha comigo o meu estilo de vida }\end{array}$ & & $\mathrm{x}$ \\
\hline Crescimento & $\begin{array}{l}\text { Acho que a minha família concorda com o meu desejo de encetar novas } \\
\text { atividades ou de modificar o meu estilo de vida }\end{array}$ & & $\mathrm{X}$ \\
\hline Afeto & $\begin{array}{l}\text { Estou satisfeito com o modo como a minha família manifesta a sua afeição } \\
\text { e reage aos meus sentimentos, tais como irritação, pesar e amor }\end{array}$ & & $\mathrm{X}$ \\
\hline Dedicação & Estou satisfeito com o tempo que passo com a minha família & & $\mathrm{X}$ \\
\hline
\end{tabular}

\section{Discussão}

O ciclo vital representa o processo evolutivo pelo qual a família passa ao longo da vida, incluindo etapas com problemas previsíveis e tarefas especificas a serem cumpridas. Manejar adequadamente esses problemas promove o bem-estar e o crescimento de todos os seus membros. ${ }^{5,6}$

Tendo por base estes princípios figurou-se como essencial enquadrar esta família na fase do seu ciclo de desenvolvimento, verificando-se pertencer à fase VIII, ou seja, ao último estágio da história de desenvolvimento, caracterizado por questões relacionadas como a velhice - perdas de habilidades e aumento dos índices de dependência. ${ }^{2}$

O Apgar familiar é um instrumento que se propõe aferir o grau de funcionalidade familiar. O resultado desta escala foi obtido por autopreenchimento, espelhando a pouca satisfação expressa de forma espontânea ao longo da entrevista.

Apesar de, sob a forma de discurso, José explicar com clareza a distância relacional entre os diferentes elementos do seu meio, quando solicitado a fazer a tradução gráfica do que explicava, hesitava, mostrando incompreensão. A insistência e explicação de forma mais acessível, com fornecimento de exemplos permitiu, no entanto, superar a dificuldade inicial, permitindo obter a representação gráfica exposta, na Figura 1.

A dificuldade em conseguir obter dos doentes este exercício de tradução gráfica, alerta para as limitações que a aplicação deste instrumento representa muitas vezes ao nível da população com baixa literácia, idosos... A virtude de concentrar tão grande riqueza informativa num esquema de extraordinária facilidade em termos de leitura, justifica, no entanto, o esforço de o tentar obter junto dos doentes, ainda que em muitos casos um forte investimento tenha de ser realizado para que o conceito seja percebido e o indivíduo se torne apto a desenvolve-lo. Feita esta ressalva, importa agora focar a atenção na análise do resultado obtido e do qual sobressai a relação de plena comunhão que José considera ter com Maria. Quando confrontado com essa constatação, José comenta "sou eu o único que lhe valho", "se não fosse eu"...

Merece ainda referência a proximidade e destaque atribuído ao Centro de Dia e ao Centro de Saúde; de fato, José coloca estas duas instituições numa posição cimeira, que surge nomeadamente à frente dos quatro filhos do casal.

\section{Contexto clínico}

Maria, portadora de múltiplas comorbidades (diabetes mellitus tipo 2; hipertensão arterial; dislipidemia; síndrome demencial, incontinência urinária e fecal), é internada em 14 de julho de 2014 para estudo de lesões 
cutâneas dispersas, tipo vesículas, com tamanho variável entre $1-3 \mathrm{~cm}$ de diâmetro, inicialmente localizadas no dorso, com posterior extensão para a face anterior do tronco e membros. Durante o internamento de 9 dias, no serviço de Medicina foi observada por dermatologia, tendo sido estabelecido o diagnóstico de pênfigo bolhoso, de provável etiologia iatrogênica (furosemida). Foi instituída corticoterapia sistêmica, com melhoria do quadro clínico, tendo a doente tido alta com prednisolona, 30mg, em esquema de desmame.

Em 30 de julho de 2014, retorno da utente ao serviço de urgência (SU) por hiperglicemia. Constatado que a doente tinha incorporado a prednisolona, $30 \mathrm{mg}$, na sua medicação habitual, não tendo realizado o esquema de desmame preconizado. A doente manteve-se internada durante 12 dias, período em que foi realizado ajuste terapêutico, com insulinoterapia. Na data de alta, um filho e uma filha disponibilizaram-se para administrar a insulina (o filho) e ajudar o marido na alimentação e restantes cuidados (ambos). Foi contactada a médica assistente para continuação de cuidados.

Na primeira visita domiciliar, realizada pela médica de família, foi verificada resolução das lesões cutâneas, permitindo progredir no desmame da corticoterapia; mas manutenção de um inadequado controlo metabólico.

Tendo-se ainda constatado que Maria tinha perdido a capacidade de marcha, pelo que passava os dias limitada ao leito, sendo cuidada pelo marido, que assumiu isoladamente o papel de vigilância e apoio a Maria (exceto a preparação de refeições e higiene que continuou a ser assegurada pelo Centro de Dia, que passou a prestar estes cuidados no domicílio).

Face a esta situação, José expressava a sua profunda tristeza pelo abandono a que os filhos os votavam (Apgar familiar 0 - família severamente disfuncional (Tabela 1), bem como a sua apreensão relativamente a um futuro que augurava desamparado.

\section{Problemas identificados}

- Situação de dependência de Maria, nas atividades básicas de vida diária, sem suporte sociofamiliar adequado.

- Sobrecarga de José, também ele idoso e sem condições físicas para desempenhar as funções de cuidador principal.

- Situação financeira frágil que compromete a contratação de apoio privado que auxilie na prestação de cuidados a Maria.

\section{Intervenção}

Perante à problemática de agravamento do estado de dependência funcional de Maria, considerou-se essencial atuar no sentido de conjugar uma rede de apoios formais e informais (que ultrapassa-se a figura do marido), na convicção de que os cuidados ao doente sem autonomia funcional deve resultar de um esforço conjunto da família e da sociedade.

Foram assim levadas a cabo as seguintes ações:

Ativação do serviço de ação social, com várias intervenções no sentido de envolver os filhos no cuidado à utente, responsabilizando-os. Perante o insucesso desta tentativa, marcado pela recusa destes em colaborar na assistência à mãe (potenciado por conflitos interpessoais entre os irmãos), foi decido comunicar a situação ao Ministério Público, que determinou, que de forma rotativa, cada um dos filhos participaria na prestação diária de cuidados à utente. 
Encaminhamento da utente para a Unidade de Cuidados Continuados Integrados -estrutura funcional da responsabilidade dos cuidados de saúde primários, formada por uma equipe multidisciplinar que visa a prestação de cuidados de saúde e de apoio social de forma continuada e integrada a pessoas que se encontram em situação de dependência. Pretendendo-se com esta orientação integrar a utente num programa de reabilitação motora, no âmbito do domicílio, visando restabelecer a sua capacidade de marcha.

Monitorização regular do cumprimento do plano de cuidados, nomeadamente vigilância ativa relativamente a possíveis situações de maus tratos ou violência (exercidos pelos filhos, dada a existência de história prévia de conflitos, distanciamento afetivo e falta de motivação para atuarem como cuidadores).

Progressivo ajustamento do esquema de insulinoterapia.

\section{Evolução}

- Resolução do pênfigo, sem necessidade de corticoterapia sistêmica;

- Melhoria progressiva do controle metabólico, da DM tipo 2;

- Manutenção do apoio diário prestado pelos filhos, sem registro de incidentes;

- Melhoria da força muscular e de equilíbrio da utente, com recuperação da capacidade de marcha, permitindo a sua reintegração na atividade de centro de dia.

\section{Considerações finais}

Do que foi exposto, depreende-se que o médico de família deverá assumir em termos de atuação um modelo integrador do doente no seu contexto familiar e social, tomando-o em consideração na mobilização de recursos que ajudem a superar a crise. De fato, perante a nova realidade socioeconômica do país, crescentes desafios se colocam ao médico de família, ao qual cada vez mais é exigido um papel ativo, ao nível da gestão de meios/recursos comunitários, e, também, se necessário de defesa do doente na interface de cuidados, ${ }^{7,8}$ nomeadamente na responsabilização da família na obrigação de cuidar dos seus membros. Isto numa lógica de que a solidariedade pública e a solidariedade familiar se consubstanciam num movimento circular e sinérgico entre gerações, tradutor de uma lógica de complementaridade e não de concorrência ou exclusividade. ${ }^{9}$

Reconhece-se, no entanto, que o processo de negociação entre os diferentes elementos da rede de parentesco é condicionado por diversos princípios, lógicas e critérios, que orientam a interação e influenciam o tipo de estratégias a adotar para viabilizar o apoio. ${ }^{10}$

Fenômeno este enfatizado no caso particular acima relatado, no qual ficou evidente o obstáculo que o evidente distanciamento afetivo entre filhos e pais constituiu na criação de uma rede de apoio adequada às necessidades da utente.

Da análise reflexiva deste caso, ressalta ainda o papel de relevo que assumiu a aplicação dos instrumentos de avaliação familiar, ferramentas que Silveira Filho conceitualizou como tecnologias relacionais, oriundas da sociologia e da psicologia, que visam estreitar a relação entre profissionais e família, promovendo a compressão em profundidade do funcionamento do indivíduo e das suas relações com a família e a comunidade. ${ }^{11}$ 
Trabalhar com esta família exigiu compreender a complexidade subjacente à dinâmica relacional dos seus membros, ponto-chave no reconhecimento da situação de vulnerabilidade, que levou à implementação de intervenções sociais e programas de saúde, cujo papel se viria a revelar crucial no processo de recuperação de Maria.

Outro aspecto que importa relevar prende-se com a importância de perceber a dependência como um processo dinâmico. De fato, situações há, em que a sua evolução se pode modificar mediante uma intervenção adequada, como bem exemplificou o caso relatado. Como tal, é fundamental que o médico de família incorpore na sua prática clínica uma avaliação funcional, visando à identificação dos casos com potencial de reabilitação, no sentido de proporcionar as condições necessárias à recuperação da autonomia.

Em suma, enfatiza-se a necessidade do médico de família atuar como agente promotor da cooperação/ articulação entre os diferentes grupos-formais e informais, no sentido de melhorar o apoio aos idosos dependentes, potencializando-os numa resposta eficaz. Neste âmbito, a necessidade de corresponsabilizar a família pela prestação de cuidados, enquanto núcleo privilegiado para o equilíbrio e bem-estar da pessoa idosa em situação de dependência, não pode ser esquecido. Pelo que nestas circunstâncias se revela imprescindível proceder ao estudo sistemático da estrutura e dinâmica familiar, no sentido de identificar recursos e implementar as intervenções necessárias à proteção dos seus membros mais vulneráveis. Alerta-se, no entanto, para a necessidade de supervisionar de perto a prestação de cuidados realizados por familiares pouco motivados, devido ao risco de maus tratos ou negligência.

\section{Referências}

1. Areosa SVC, Areosa AL. Envelhecimento e dependência: desafios a serem enfrentados. Textos Contextos (Porto Alegre). 2008;7(1):138-50.

2. Silva JV, Santos SMR. Trabalhando com famílias utilizando ferramentas. Rev APS. 2003;6(2):77-86.

3. Machado H, Soprano ATB, Machado C, Lustosa ACP, Lima MH, Mota ACG. Identificação de riscos na família a partir do genograma. Fam Saúde Desenv. 2005;7(2):149-57.

4. Mello F, Vieira S. Genograma e ecomapa: possibilidades de utilização na estratégia de saúde da família. Rev Bras Crescimento Desenvolv Hum. 2005;15(1):81-91.

5. Falceto OG, Fernandes CLC, Wartchow ES. O médico, o paciente e sua família. In: Duncan BB, Schmidt MI, Giugliani ERJ. Medicina ambulatorial: condutas de atenção primária baseadas em evidências. 3a ed. Porto Alegre: Artmed; 2004. p.115-24.

6. Elsen I. Cuidado familial: uma proposta inicial de sistematização. In: Elsen I, Marcon SS, Silva MRS, orgs. O viver em família e sua interface com a saúde e a doença. 2a ed. Maringá: Eduem; 2004. p.11-24.

7. Sampaio D, Resina T. Família: Saúde e Doença. Lisboa: Instituto de Clínica Geral da Zona Sul; 1994.

8. Allen J, Gay B, Crebolder H, Heyrman J, Svab I, Ram P, et al. A Definição Europeia de Medicina Geral e Familiar (Clínica Geral/Medicina Familiar): versão reduzida. Lisboa: EURACT; 2005.

9. Attias-Donfut C. Les solidarités entre générations. Vieillesse, familles, État. Paris: Nathan; 1995.

10. Pimentel LG, Albuquerque CP, Solidariedades familiares e o apoio a idosos. Limites e Implicações. Textos Contextos (Porto Alegre). 2010;9(2):251-63.

11. Silveira Filho AD, Oliveira CA, Ribeiro EM, Lopes MGD. Programa Saúde da Família em Curitiba: estratégia de implementação da vigilância à saúde. In: Ducci L, Pedotti MA, Simão MG, Moysés SJ. Curitiba: a saúde de braços abertos. Rio de Janeiro: CEBES; 2001. p.239-51. 